\title{
Signal processing techniques for identification of plant diseases
}

\author{
Gyan Vardhan Singh* and Pooja Singh
}

Department of Electronics and Communication Engineering, Amity University, Lucknow Campus, Lucknow (U.P.) India

\section{ARITCLE INFO \\ Received : 08.07.2019 \\ Revised : 03.09.2019 \\ Accepted : 17.09 .2019}

\section{KEY WORDS :}

Powdery Mildew, Alternaria Alternata, Anthracnose, Hue based segmentation, Image processing, Feature extraction, Multi-SVM classifier

*Corresponding author:

Email : singh.gyanvardhan @gmail.com

\begin{abstract}
Plant pathology is a vast science with far reaching impact on human civilization. Selfsufficiency in food production is important for overall prosperity of any Modern Economy. Currently with the advance in overall Agricultural/Horticultural sciences, our overall Food production has been good. However, we neglect the often important factor of disease out-breaks which have economically affected the farmers at different instances. Sometimes, few diseases or symptoms are well known to farmers and could be easily diagnosed and in other cases, expert opinion is required, which is often not easily available. With the advent of cloud computing, penetration of mobile phones and availability of high-speed network, it is very easy to implement soft system, which could help our farmers identify different diseases based on image data captured by their mobile phone. To demonstrate the concept in this paper Alternaria Alternata, Anthracnose, Powdery Mildew in different species like Grape, tomato and Jute is considered. We discuss and implement feature extraction module to objectively construct a disease signature/ unique marker that could be used for specific disease identification across species irrespective of Plant type. In line with this strategy, a software architecture for Tele-pathology in plants is structured such that different diseases could be categorized. In a very short period of time, expert knowledge in the field of Plant Pathology could be objectified into easily usable tools and this would complement the already existing classical extension activities.
\end{abstract}

How to view point the article : Singh, Gyan Vardhan and Singh, Pooja (2019). Signal processing techniques for identification of plant diseases. Internat. J. Plant Protec., 12(2) : 132-137, DOI : 10.15740/HAS/IJPP/12.2/132-137, Copyright@ 2019: Hind Agri-Horticultural Society. 